\title{
A continuous flow probe method for on-line introduction of liquid samples for detection by laser desorption with resonant two-photon ionization in supersonic beam mass spectrometry
}

\author{
David A. Lustig and David M. Lubman \\ Department of Chemistry, The University of Michigan, Ann Arbor, Michigan 48109
}

(Received 8 October 1990; accepted for publication 7 December 1990)

\begin{abstract}
A continuous flow probe is used as a direct inlet source for injection of liquid samples into a time-of-flight (TOF) mass spectrometer. The direct liquid inlet is coupled to laser desorption as a means of rapidly vaporizing the nonvolatile sample dissolved in the solvent for entrainment into a supersonic jet expansion. The target analyte is then selectively analyzed by resonance enhanced multiphoton ionization (REMPI) in the TOF device. This method demonstrates the ability to continuously inject thermally labile biological samples such as neurotransmitters and oligopeptides for detection and structural analysis by REMPI. In addition, sensitivity limits in the low ng regime are demonstrated with quantitation over 3 orders of magnitude.
\end{abstract}

\section{INTRODUCTION}

Resonance enhanced multiphoton ionization (REMPI) has been shown to be a method providing enhanced sensitivity and selectivity for chemical analysis. ${ }^{1-3}$ This method has been applied quite extensively for detection and identification of volatile organic molecules with strong absorbing chromophores in the near UV and visible regions of the spectrum. REMPI has the added advantage that since ions are produced as the final product, exact identification can be obtained via mass analysis in a mass spectrometer. In addition, by carefully controlling the laser power and frequency, often soft ionization with production of the molecular ion can be achieved. However, by increasing the laser power or frequency, one can increase the total energy placed in the molecule thus resulting in fragmentation for structural analysis as an additional identification tool.

In more recent work, REMPI has been extended to nonvolatile and labile biological molecules using a number of different volatilization techniques. ${ }^{1-10}$ Direct heating methods can be used to volatilize relatively stable large polynuclear aromatic hydrocarbons (PNAHs) with high melting points. This has been performed using hot pulsed or continuous ovens ${ }^{11,12}$ or high temperature gas chromatography for injection as jet expansions with REMPI detection. ${ }^{13-15}$ Other more specialized heating methods have been used to volatilize the amino acid tryptophan and other related indoleamines into a jet of $\mathrm{He}$ carrier gas for REMPI detection. ${ }^{8}$ However, for compounds of biological interest which tend to become increasingly more labile, direct heating methods usually result in thermal decomposition.

A powerful method for volatilizing thermally labile molecules is laser desorption. ${ }^{1-10}$ In this method, a highpowered pulsed infrared laser is used to induce a rapid heating that desorbs molecules from a surface before they have time to decompose. ${ }^{16}$ In this process both ions and neutrals are formed in a ratio that depends to a first approximation on the surface temperature induced by the laser. The actual number of ions produced in the desorption process is gencrally quite small compared to the large number of neutral species that result at power densities below $10^{8} \mathrm{~W} / \mathrm{cm}^{2}{ }^{17}$ In previous work, a relatively lowpowered pulsed $\mathrm{CO}_{2}$ laser $\left(\sim 10^{6} \mathrm{~W} / \mathrm{cm}^{2}\right)$ has been used to generate a plume of neutral species that are then entrained into a pulsed supersonic jet and transported to a TOF mass spectrometer for study by REMPI spectroscopy. ${ }^{4,6,8}$ This method has been used for REMPI/MS identification and structural analysis of various classes of labile molecules including small peptides, nucleosides, drugs, neurotransmitters and polymers. ${ }^{1-10}$ In initial work, desorption was performed from relatively thick bulk samples. However, IR laser-induced desorption of material has been performed out of viscous liquid matrices such as glycerol or diffusion pump oil, ${ }^{4}$ and more recently has been performed from a liquid propanol matrix from the tip of a capillary direct liquid injection probe. ${ }^{18}$ Desorption from liquid matrices has several advantages including: (1) acting as a heat sink to prevent thermal decomposition in the bulk desorption process and (2) allowing a method for continuous desorption from the same spot with excellent pulse-to-pulse stability for spectroscopic scanning REMPI experiments. ${ }^{4}$

In the experiments to date, laser desorption has been performed from static samples. In the work presented herein, laser desorption is interfaced to a direct inlet continuous flowing interface for on-line injection of biological samples for analysis by REMPI. The technique of fast atom bombardment (FAB) MS has recently been interfaced to such a continuous-flow liquid injection. ${ }^{19,20}$. This method provides the distinct advantages of: (1) on-line analysis in combination with microbore HPLC; (2) provides a dynamic means of studying molecules in a changing environment, i.e., for enzymatic digestion of peptides; and (3) overcomes some of the basic disadvantages of FABMS, such as the suppression effect where highly hydrophilic peptides often do not migrate to the glycerol surface in the presence of peptides with a more hydrophobic character 

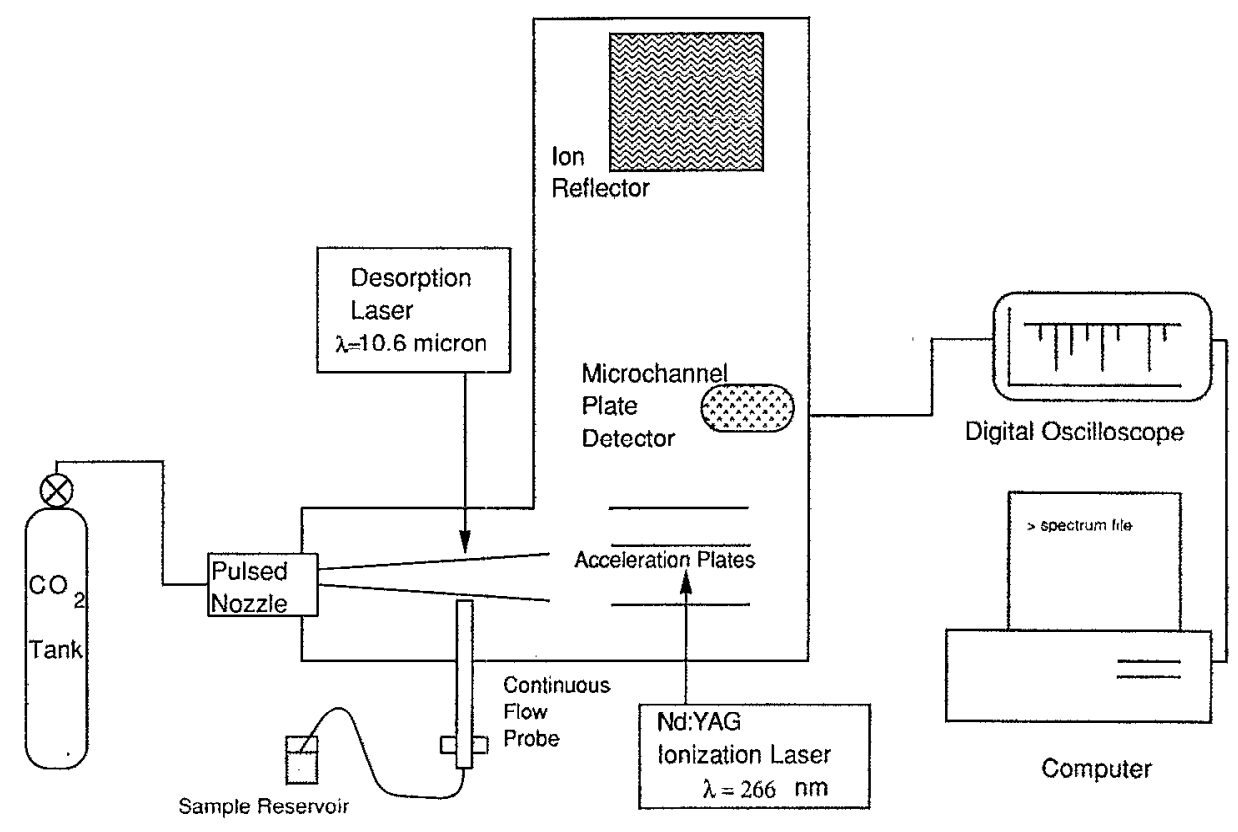

FIG. 1. Schematic of experimental apparatus.

and thus are not readily detected by FAB. However, continuous flow FAB is often plagued by chemical noise from the matrix at low masses as is static FAB, although to a lesser extent. In this work laser desorption is interfaced to such a flowing injection system into a mass spectrometer as a means of rapidly volatilizing the labile sample for on-line and continuous injection. This method provides the distinct advantage of continuous and long-term injection of sample for REMPI analysis as opposed to the static method where only a limited amount of sample is available for study. In addition, it provides a method for direct injection of liquid samples into vacuum for REMPI detection and also provides the possibility of on-line analysis in combination with HPLC. We demonstrate the design of a flow probe for direct liquid injection with laser desorption/ evaporation and the subsequent selective and sensitive detection of a variety of labile biological species by REMPI/ MS. In addition, we demonstrate selective detection of target molecules without interference from the matrix which remains transparent to the laser radiation or from interference due to chemical noise at low masses.

\section{EXPERIMENT}

\section{A. System}

The experimental setup is shown in Fig. 1. It consists of a reflectron TOF mass spectrometer (reTOF) mounted in an 8 in. conflat stainless steel four-port cross. The chamber is pumped by a $\mathbf{L N}_{2}$ cold-baffled 6 in. VHS diffusion pump, while the reTOF flight tube is pumped by a 4 in. $\mathrm{LN}_{2}$ cold baffled VHS diffusion pưmp. Typically a background pressure of $7 \times 10^{-7}$ Torr is achieved in this configuration. A pulsed supersonic molecular beam expands into the acceleration region of the reTOF and a UV laser beam perpendicular to both the jet and fight tube enters and exits the chamber through quartz windows and ionizes the sample. The supersonic beam source is a stain-

less steel pulsed valve $(0.5 \mathrm{~mm}$ aperture diameter $)$, based on the magnetic repulsion principle ( $R$. M. Jordan Co.) which can provide gas pulses of $\sim 55 \mu \mathrm{s}$ FWHM at "choked flow" at a $10 \mathrm{~Hz}$ pulse rate, thus substantially reducing the duty cycle needed for pumping. In addition, a liquid $\mathrm{N}_{2}$ cold-finger trap is inserted into the chamber in order to enhance pumping of liquid and of background from diffusion pump oil. In these experiments, $\mathrm{CO}_{2}$ is used as the carrier gas and the average background pressure during operation remains at $\sim 7 \times 10^{-6}$ Torr since $\mathrm{CO}_{2}$ is efficiently cryopumped by the $\mathrm{LN}_{2}$ trap.

The general experimental scheme involves using a continuous flow probe (CFP) for direct injection of liquid samples into the reTOF. The CFP enters the mass spectrometer through a vacuum lock, consisting of a Whitey valve pumped by a mechanical pump. The probe enters the chamber just above the ionization region and just below the pulsed valve orifice such that it is on-axis with both of these. The $\mathrm{CO}_{2}$ desorption laser beam enters the reTOF through a $\mathrm{NaCl}$ window located opposite the CFP. The desorption beam is externally focussed by a $\mathrm{ZnSe}$ lens to a spot $\sim 2 \mathrm{~mm}$ on the CFP tip. The power density of the desorption beam is $\sim 10^{5}-5 \times 10^{6} \mathrm{~W} / \mathrm{cm}^{2}$ per pulse, producing primarily gas phase neutrals of the analyte and matrix. The desorbed neutral molecules are entrained into the pulsed jet which transports them into the ionization region of the reTOF. Ionization is performed using the fourth harmonic of a Nd:YAG laser $(266 \mathrm{~nm})$. The laser beam is collimated to $2 \mathrm{~mm}$ diameter through the combination of a convex lens $(30 \mathrm{~cm} \mathrm{f.1.)}$ and a concave lens $(10 \mathrm{~cm} \mathrm{f.1.)}$. Typical operation of the Nd:YAG laser is at $10 \mathrm{~Hz}$ with power densities ranging from $10^{5}-10^{7} \mathrm{~W} / \mathrm{cm}^{2}$ for varying degrees of fragmentation.

The actual sequence of events was controlled by several delay generators where the pulsed $\mathrm{CO}_{2}$ laser fires first to produce desorption followed by the pulsing of the valve. The two events were synchronized in time so that the de- 


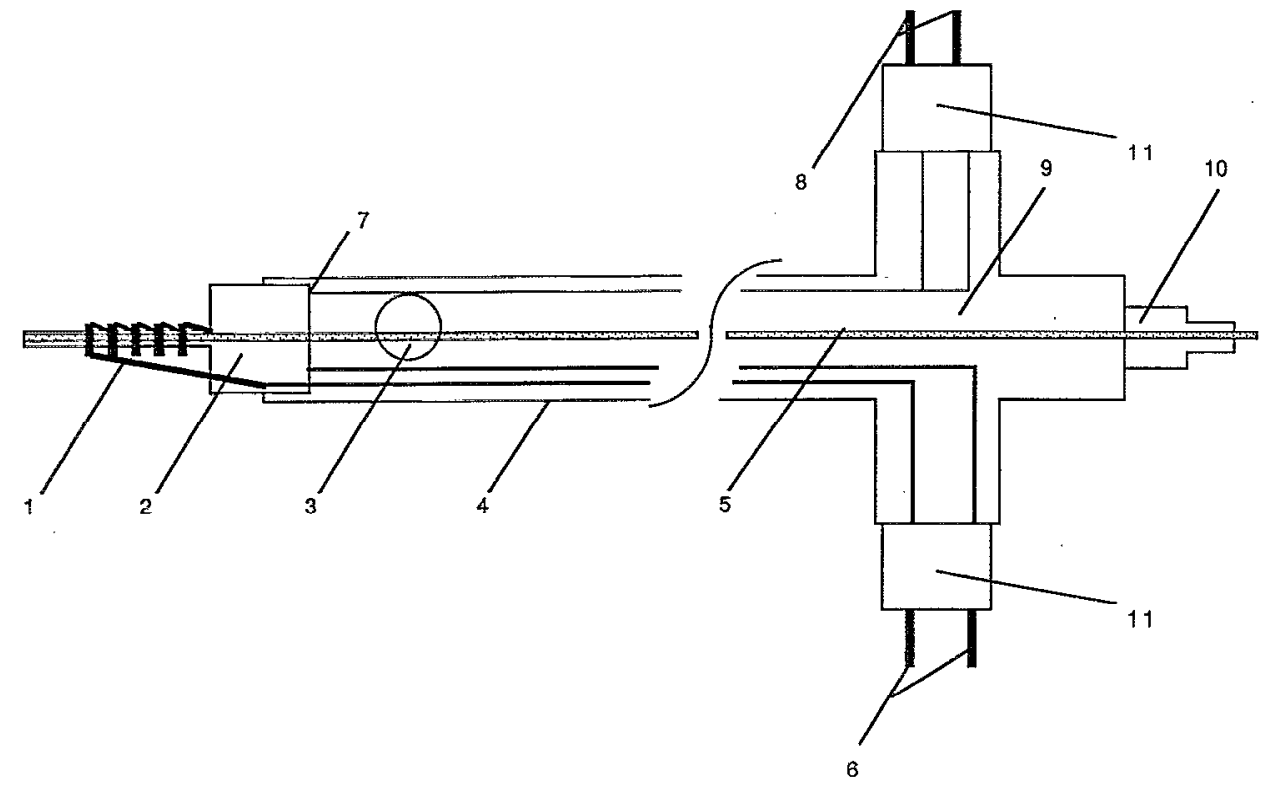

FIG. 2. Schematic of laser desorptioncontinuous flow probe, where (1) resistive heating element (insulated), (2) brass probe tip, (3) pumping port, (4) stainless steel probe body, (5) fused silica microbore capillary tubing, (6) electrical leads to heating clement, (7) thermocouple, (8) electrical leads to thermocouple, (9) $\frac{1}{2}$ in. Cajon stainless steel cross (one face removed), (10) standard $\frac{1}{8}$ in. LC Male Fitting (soldered to $\frac{1}{2}$ in. disk), (11) electrical feed throughs (constructed in-house). sorbed plume was entrapped into the jet expansion of $\mathrm{CO}_{2}$ and carried into the acceleration region of the reTOF. The flight time of the jet from the pulsed valve to this region was $\sim 300 \mu \mathrm{s}$, and the laser was, therefore, set to pulse as the gas pulse arrived at this point. Laser R2PI was produced and a LeCroy 9400 digital oscilloscope interfaced to an IBM compatible computer for data storage was used to record the mass spectrum. The digital oscilloscope is equipped with a signal averaging function and all spectra presented result from a single laser shot or are the average of 50 individual spectra unless otherwise specified.

\section{B. Sample preparation}

The analyte is dissolved in an appropriate solvent such as $\mathrm{CH}_{3} \mathrm{OH}, \mathrm{H}_{2} \mathrm{O}, \mathrm{CH}_{3} \mathrm{CN}$, or ethylacetate or various mixtures of these solvents that provide the best solubility. When microbore tubing $76 \mu \mathrm{m}$ diameter was used as the injection source then typically $3 \%-20 \%$ glycerol and $5 \%$ ethylene glycol was added to the solvent. The glycerol is needed in order to limit the liquid flow rate into the mass spectrometer so that the vacuum system is not overloaded and so that the sample flows out evenly across the face of the CFP tip for laser desorption. Ethylene glycol was used to prevent freezing and clogging of the narrow bore tubing. The glycerol content in this case was typically $10 \%$, while $>50 \%$ glycerol resulted either in a flow that was too slow for our experiments or clogging of the tip. When tubing $>100 \mu \mathrm{m}$ was used, a glycerol concentration of $>60 \%$ could be used and no ethylene glycol was required. This reduced the pumping requirements considerably for larger bore diameter capillaries and allowed an even injection of material into the reTOF. The larger diameter capillary also has the distinct advantage of not clogging in these experiments, while even under the best conditions the $76 \mu \mathrm{m}$ capillary was found to clog after several hours of use. In the case of the quantitative studies where the sample was injected via a syringe into an injection loop and subsequently into a flow of carrier pumped by a syringe pump, the samples were prepared in pure methanol but the carrier solution was generally $60 \%$ glycerol $/ 40 \% \quad \mathrm{CH}_{3} \mathrm{OH}$ (vol:vol). The liquid samples and carrier solutions were filtered through a stainless steel frit and then placed into a 5 or $10 \mathrm{ml}$ vial that served as a sample reservoir and/or for storage.

\section{Continuous flow probe design}

The design of the flow probe for liquid injection is shown in Fig. 2. It consists of the probe body, the probe desorption tip, and the microbore capillary tubing that delivers sample to the face of the tip.

\section{Probe body}

The probe body is constructed of a $\frac{1}{2}$ in. Cajon ${ }^{\mathrm{TM}}$ Ultratorr fitting stainless steel cross and a stainless steel tube ( $\frac{1}{2}$ in. o.d., $\frac{3}{8}$ in. i.d.). The fitting from one side of the Cajon ${ }^{\mathrm{TM}}$ cross is removed. The blank side of the cross is silver soldered to the stainless steel tube to form the CFP body. In addition, a $\frac{3}{8}$-in.-diam. hole is drilled into the shaft of the body in order to pump out the probe.

\section{Probe tip}

The probe tip was constructed of brass in order to optimize heat transfer to the tip. A small hole is drilled into the center of the face of the CFP tip which is just large enough $(0.014 \mathrm{in}$.) to allow the capillary tubing that carries the sample to pass through the tip. This setup holds the capillary tubing in a fixed position on axis with the desorption laser beam and the pulsed nozzle molecular beam. The microbore capillary tubing is flush with the CFP tip. At the face there is a recessed area $0.025 \mathrm{in}$. deep with a $0.08 \mathrm{in}$. o.d. The sample flows out across this area and laser desorption is performed at this surface.

The probe tip is heated by an insulated resistive element. Such heating is necessary since the expansion of the liquid from the probe into the vacuum is accompanied by cooling and the liquid will freeze and block the capillary. A 
thermocouple monitors the tip and provides feedback to a heating controller to maintain a constant temperature, typically $40^{\circ} \mathrm{C}-100^{\circ} \mathrm{C}$. Feedthroughs for the resistive heating element and the thermocouple are mounted on opposite faces of the Cajon ${ }^{\mathrm{TM}}$ cross. The feedthroughs are constructed by drilling holes in $\frac{1}{2}$ in. stainless steel plugs. The wires are drawn through the holes and fixed into place with Torr Seal vacuum epoxy. The plug then fits into the $\frac{1}{2}$ in. $\mathrm{Cajon}^{\mathrm{TM}}$ port with an O-ring seal. The result is a vacuum tight feedthrough that is easily removed when necessary.

The microbore capillary tubing runs the length of the probe and delivers sample to the face of the tip. The two sizes of tubing used in this experiment were $76 \mu \mathrm{m}$ i.d. $\times 367 \mu \mathrm{m}$ o.d. and $103 \mu \mathrm{m}$ i.d. $\times 358 \mu \mathrm{m}$ o.d. (Polymicro Technologies, Phoenix, AZ). The best results were observed with the $103 \mu \mathrm{m}$ tubing. Although filtered carrier solvents and samples were used, the $76 \mu \mathrm{m}$ tubing was found to clog after being used for $5-10 \mathrm{~h}$.

At the vacuum end of the probe, the capillary tubing is epoxied into the back of the CFP tip. Although the hole in the tip through which the tubing passes is just slightly larger than its o.d., this was found not to provide sufficient thermal contact to prevent freezing during expansion. However, freezing was prevented by fixing the tubing into the back of the tip with a special heat conducting epoxy (Epoxy \#905, Epoxy Technologies, Billerica, MA).

At the atmospheric pressure side of the probe, the microbore capillary tubing passed through a feedthrough. This feedthrough was constructed of a standard stainless steel $\frac{1}{8}$ in. male LC fitting that was silver soldered to $a \frac{1}{2}$ in. stainless steel disk. The disk made a vacuum seal with the $\frac{1}{2}$ in. Cajon ${ }^{\mathrm{TM}}$ port on the cross. The capillary tubing was fixed into the LC fitting with Torr Seal vacuum epoxy. The capillary tubing either extends beyond the feedthrough or is cut off flush with the feedthrough depending on which method of sample delivery was used.

\section{Sample delivery}

The sample is introduced into the CFP by two methods in these experiments. In order to obtain continuous REMPI mass spectra of biologicals a continuous injection was used. In this case, the microbore tubing protrudes from the CFP and is placed directly into a reservoir containing the dissolved sample. The sample is carried up the capillary by the vacuum of the mass spectrometer.

Alternatively, for quantitative measurements a syringe pump is used to pump the carrier liquid which is typically $60 \%$ glycerol with the remainder being a solvent appropriate for the sample. The pump operates at $60 \mathrm{ml} / \mathrm{h}$ with a split of $\sim 150: 1$ so that the flow is reduced sufficiently for injection into vacuum. The sample is injected through a $100 \mu 1$ injector port and is transported through 0.007 in. i.d. $\times \frac{1}{16}$ in. o.d. stainless steel tubing and into the flow probe. The use of $103 \mu \mathrm{m}$ tubing in the flow probe results in a flow rate of $\sim 7 \mu \mathrm{l} / \mathrm{min}$, which is readily pumped by the vacuum system.

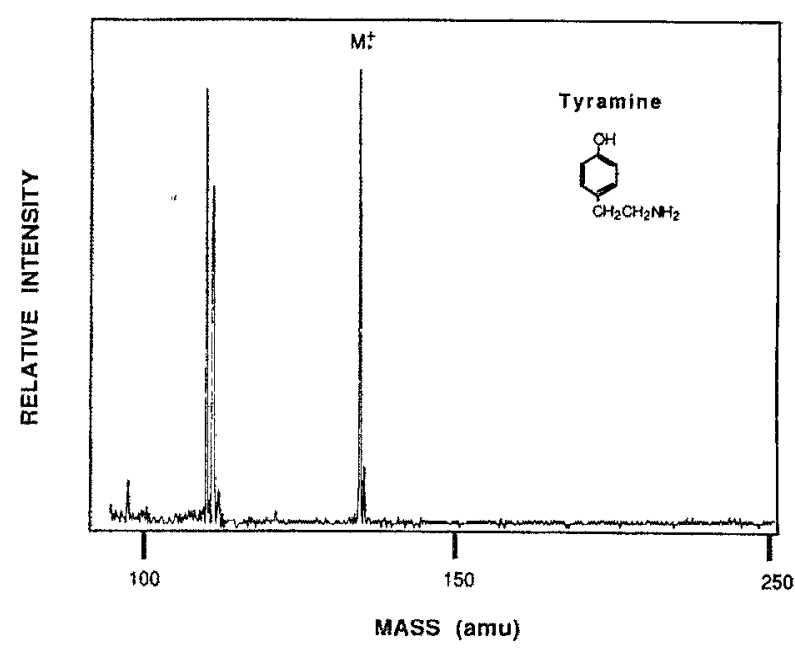

FIG. 3. REMPI mass spectrum of tyramine at $266 \mathrm{~nm}$ obtained using continuous fow injection with laser desorption/evaporation of sample from a $39 \mathrm{mM}$ solution in $\mathrm{H}_{2} \mathrm{O} / \mathrm{MeOH} /$ glycerol/cthylene glycol 45:50:2.5:2.5 (V:V) solvent.

\section{RESULTS AND DISCUSSION}

In Fig. 3 is shown a mass spectrum of tyramine obtained by liquid flow probe injection using a solution of 39 $\mathrm{mM}$ tyramine in $\mathrm{H}_{2} \mathrm{O} / \mathrm{MeOH} / \mathrm{glycerol} /$ ethylene glycol in a ratio of $45: 50: 2.5: 2.5(\mathrm{v}: \mathrm{v})$ and ionization via REMPI at $266 \mathrm{~nm}$. Sample delivery was performed using a $76 \mu \mathrm{m}$ capillary placed directly into the sample reservoir. The tip temperature was held at $40^{\circ} \mathrm{C}$ and a single laser shot spectrum was obtained. The REMPI mass spectrum yielded a strong molecular ion peak at $\mathrm{m} / z$ 137. In addition, fragment ion peaks were observed at 107 and 108. It is significant to note that only the sample is selectively ionized at $266 \mathrm{~nm}$ while there are no peaks observed from the solvent matrix, including even the glycerol or ethylene glycol. These compounds are transparent to the laser radiation and are not ionized at this wavelength.

In Fig. 4 is shown a REMPI mass spectrum $(266 \mathrm{~nm})$ of Gly-Tyr obtained using flow probe injection in a $20 \mathrm{mM}$ solution of $50: 50 \mathrm{H}_{2} \mathrm{O} /$ glycerol. In this case a $76 \mu \mathrm{m}$ capillary sampled the solution directly and the probe tip was maintained at $60^{\circ} \mathrm{C}$. The spectra obtained are an average of 50 laser pulses. At relatively low power $\left(0.3 \mathrm{MW} / \mathrm{cm}^{2}\right)$ the molecular ion was obtained with little or no fragmentation. As the laser power was increased to $0.9 \mathrm{MW} / \mathrm{cm}^{2}$ extensive fragmentation was obtained that was characteristic of the structure of the dipeptide. ${ }^{21}$ These peaks included the $\mathrm{M}^{+}$at $\mathrm{m} / \mathrm{z} 238$, accompanied by a peak at $\mathrm{m} / \mathrm{z} 220$ due to loss of $\mathrm{H}_{2} \mathrm{O}$. The ion peak at $\mathrm{m} / z 164$ results from cleavage at the $\mathrm{N}-\mathrm{C}$ (amide) bond shown in Fig. 4 while the $m / z 107$ results from $\beta$ cleavage at the tyrosine moiety. The ion at $m / z 75$ is probably the species that results from the charge residing on the other fragment resulting from the $\mathrm{N}-\mathrm{C}$ (amide) bond cleavage or so-called " $\mathrm{C}$ " fragmentation in the Roepstorff-Fohlman notation. ${ }^{22}$ The formation of the $m / z 164$ and 75 fragments are classic reaction pathways in mass spectrometry. The $m / z 75$ ion is 


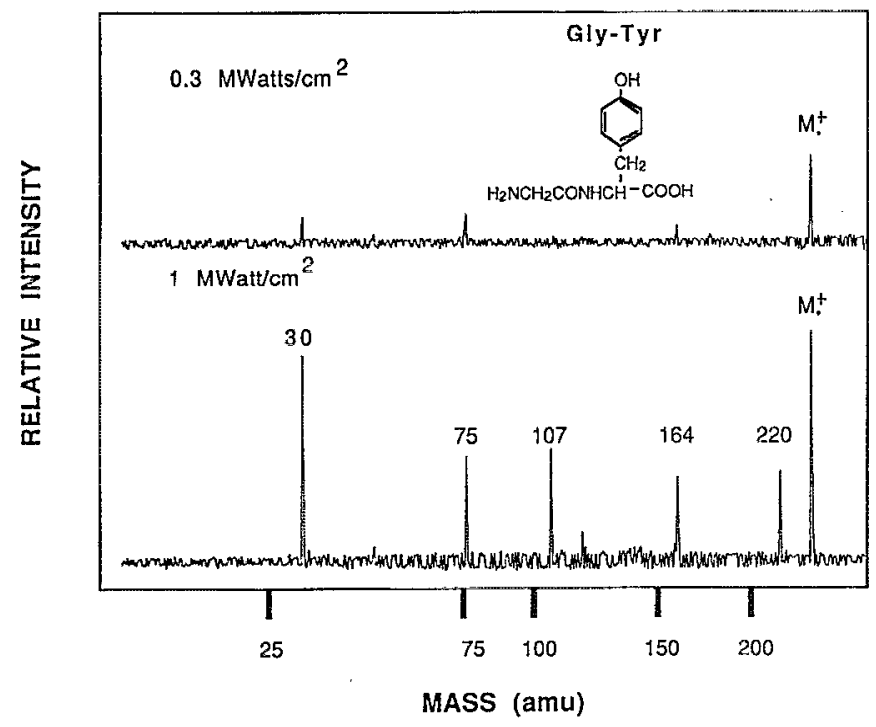

FIG. 4. REMPI mass spectrum of glycine-tyrosine ( $m w 238$ ) at $266 \mathrm{~nm}$ obtained using continuous flow injection with laser desorption/ evaporation of sample from a $20 \mathrm{mM}$ solution in $\mathrm{H}_{2} \mathrm{O} /$ glycerol $50: 50$ $(V: V)$ solvent.

formed by a double hydrogen rearrangement (McLafferty +1 rearrangement) and the $m / z 164$ ion is formed by a $\gamma$ hydrogen transfer (McLafferty rearrangement) with charge migration to this product. ${ }^{23}$ The ion at $m / z 30$ is the end alkyl amine group on the glycine.

In Fig. 5 is shown a REMPI mass spectrum of TrpGly-Gly obtained at $266 \mathrm{~nm}\left(0.3 \mathrm{MW} / \mathrm{cm}^{2}\right)$ using liquid injection with a $4.5 \mathrm{mM}$ concentration of Trp-Gly-Gly dissolved in $\mathrm{H}_{2} \mathrm{O}$ /ethylene glycol/glycerol in a 90:5:5 (v:v) ratio. The sample delivery was performed using a $76 \mu \mathrm{m}$ tubing sampling directly from the reservoir and the probe

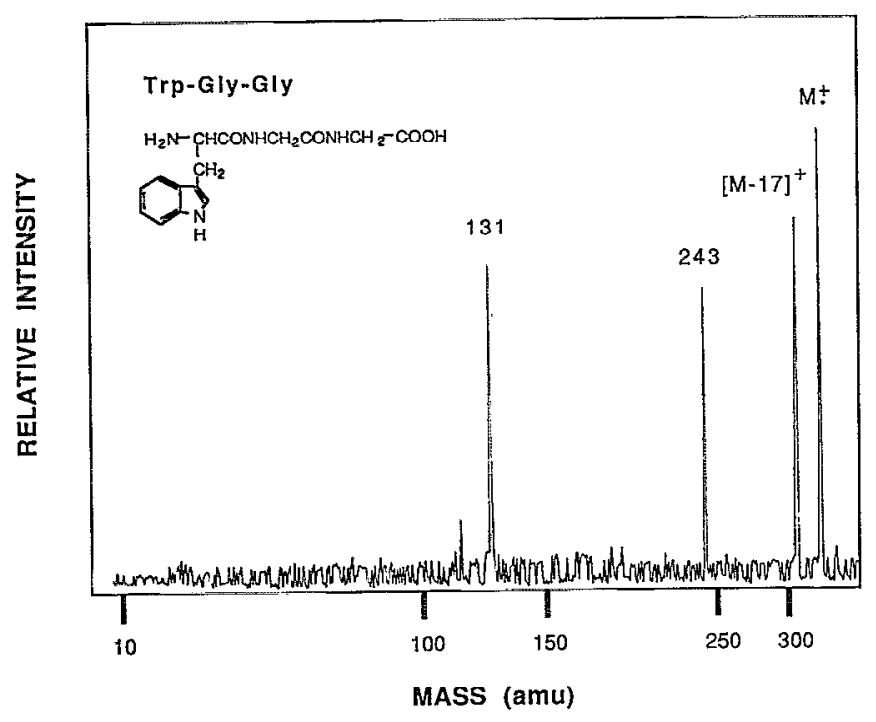

FIG. 5. REMPI mass spectrum of Trp-Gly-Gly (mw 318) at $266 \mathrm{~nm}$ ubtained using continuous flow injection with laser desorption/ evaporation of sample from a $4.5 \mathrm{mM}$ solution in $\mathrm{H}_{2} \mathrm{O}$ /ethylene glycol/ glycerol 90:5:5 (V:V) solvent.

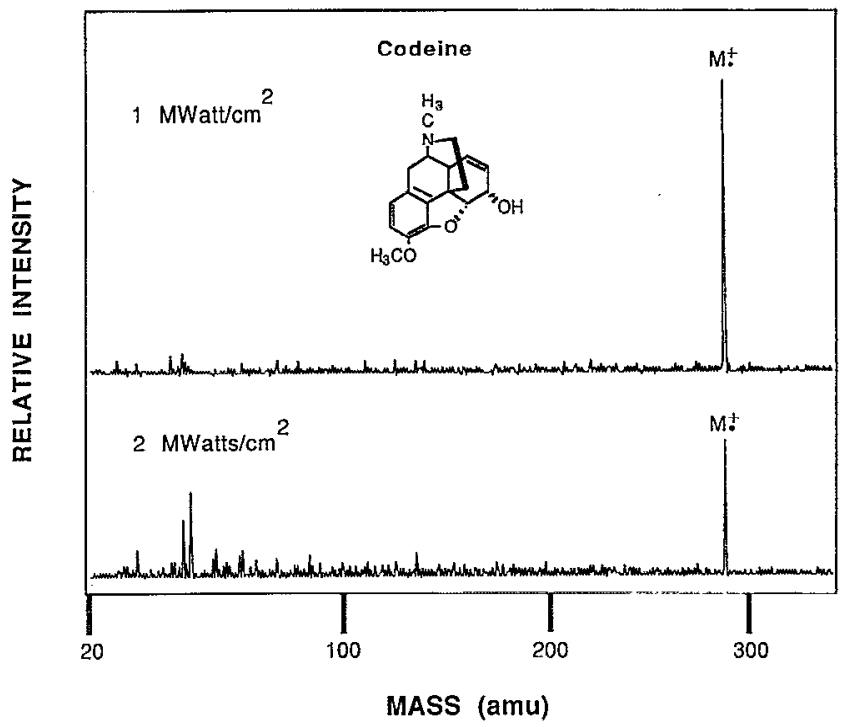

FIG. 6. REMPI mass spectrum of codeine at $266 \mathrm{~nm}$ obtained using continuous flow injection with laser desorption/evaporation of sample from a $100 \mathrm{mM}$ solution in glycerol/ $\mathrm{CH}_{3} \mathrm{OH} 60: 40(\mathrm{~V}: \mathrm{V})$ solvent.

tip was maintained at $70^{\circ} \mathrm{C}$. The spectrum is an average of 50 shots. In this case a strong molecular ion peak is obtained. In addition, a characteristic ion peak is observed at $(\mathrm{M}-17)^{+}$which corresponds to $301 \mathrm{u}$. This peak may be due to loss of $-\mathrm{NH}_{3}$ as shown by labeling studies ${ }^{24}$ or loss of $-\mathrm{OH}$ as shown more recently by high resolution FTMS work. ${ }^{25}$

In Fig. 6 is a REMPI mass spectrum of codeine injected by a continuous liquid flow of $100 \mathrm{mM}$ codeine in $60: 40$ glycerol/MeOH. This was performed using a $103 \mu \mathrm{m}$ capillary tubing to sample directly from the solution. At relatively low power $\left(1 \mathrm{MW} / \mathrm{cm}^{2}\right)$ a strong $\mathrm{M}^{+}$ion peak is observed with no fragmentation. Even as the power is increased little fragmentation is observed.

It should be noted that the role of the $\mathrm{CO}_{2}$ laser desorption is critical for efficient vaporization and entrainment of the analyte into the jet expansion. At moderate temperatures which should vaporize the solvent $\left(60^{\circ} \mathrm{C}\right.$ $120^{\circ} \mathrm{C}$ ), no signal was observed for the thermally labile compounds such as Gly-Tyr or Trp-Gly-Gly or for the stable compounds with high melting points such as codeine. However, in this temperature range a small $\mathrm{M}^{+}$. signal was observed for tyramine. This signal was over an order of magnitude smaller than that produced by laser desorption on each laser pulse. At high temperatures $\left(150^{\circ} \mathrm{C}-250^{\circ} \mathrm{C}\right)$ nearing the melting point of the compounds, a signal was observed for all compounds without laser desorption. In the case of the relatively stable compounds (i.e., codeine), $\mathrm{M}^{+}$was observed, along with some minor fragmentation. However, the spectra obtained from the unstable compounds (Gly-Tyr) showed very extensive fragmentation with little or no molecular ion. The fragments observed include several of the expected peaks ${ }^{21}$ and many others that are not easily identified. The intensity of the signal observed from heating is once again an 


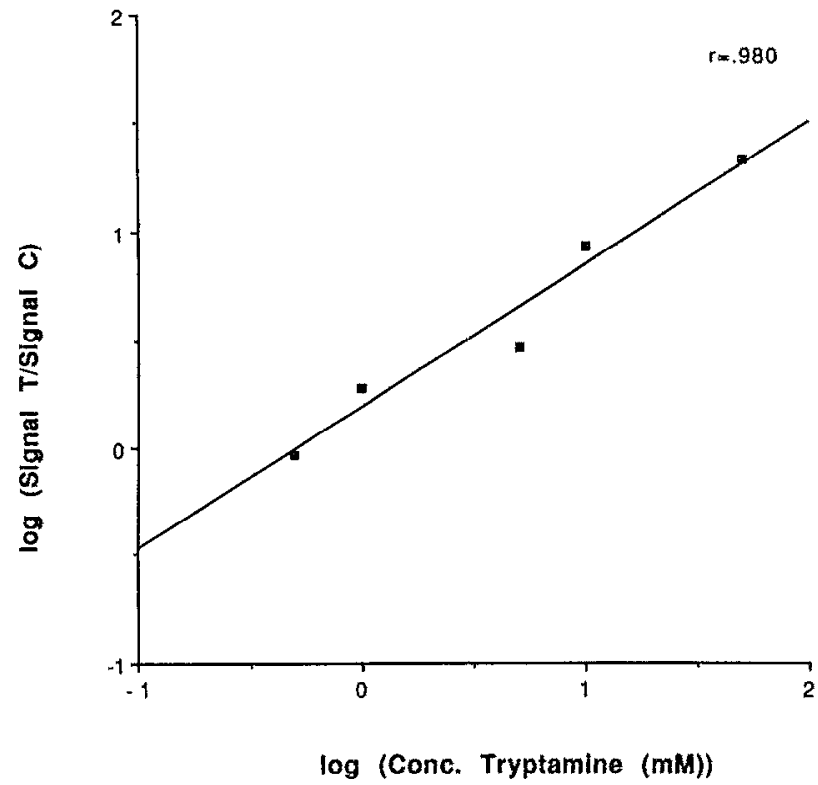

FIG. 7. Quantitative plot of tryptamine detection using codeine as an internal standard ( $\mathrm{T}=$ tryptamine, $\mathrm{C}=$ codeine).

order of magnitude or smaller than that obtained from pulsed laser desorption. At the temperatures used in this experiment, the solvent should be completely vaporized, and this experiment is essentially equivalent to heating the material from a heated probe.

A quantitation experiment was performed for tryptamine as shown in Fig. 7. Quantitation was accomplished for tryptamine using codeine as an internal standard. When the log of the ratio of the tryptamine to codeine signal was plotted versus the log of the tryptamine concentration, the results were found to be linear over at least three decades. A detection limit of $80 \mathrm{ng}$ was observed for tryptamine with a $\mathrm{S} / \mathrm{N}=3$ using a $1 \mu \mathrm{g}$ injection loop. This of course corresponds to the detection limit for the amount of sample actually injected. For comparison, the single shot sensitivity can be calculated assuming a flow rate of $7 \mu \mathrm{l} / \mathrm{min}$ to be $80 \mathrm{ng} / 1 \mu \mathrm{l} \times 0.012 \mu \mathrm{l} /$ pulse $\sim 0.96$ $\mathrm{ng} /$ pulse. This is still much higher than the $1-10 \mathrm{pg}$ single shot sensitivity for tryptamine from a static probe observed in previous work. ${ }^{1}$ Although the sensitivity of this method is not comparable to the pg level sensitivity attainable with the static probe, it does provide an excellent on-line method for continuous injection of sample for study by REMPI/MS. The sensitivity of the method appears to be limited by the ability to entrain the expanding liquid plume into the supersonic jet. Nevertheless, direct desorption from the liquid in the acceleration region of the reTOF generates significant ion current. The use of the jet entrainment transports the neutrals into the TOF while the ions are deflected away by the electric field of the TOF acceleration plates. Thus, a spectrum without chemical noise or background ions due to the desorption or the ionization step is observed.

\section{ACKNOWLEDGMENTS}

We gratefully acknowledge support of this work by Dow Chemical Co. and also by the National Science Foundation under Grant No. NSFCHE 8720401 . We thank Phil Savickas of Dow for helpful discussions during the course of this work.

'See for example, Lasers and Mass Spectrometry, edited by D. M. Lubman (Oxford University Press, New York, 1990).

'D. M. Lubman, Mass Spectrom. Rev. 7, pt. I, 535 (1988); pt. II, 559 (1988).

${ }^{3}$ J. A. Syage and J. E. Wessel, Appl. Spectrosc. Rev. 24, 1 (1988).

${ }^{+}$R. Tembreull and D. M. Lubman, Anal. Chem. 58, 1299 (1986); L. Li and D. M. Lubman, Anal. Chem. 59, 2538 (1987); Appl. Spectrosc. 42, 418 (1988); Anal. Chem. 60, 1409 (1988); Rev. Sci. Instrum. 59, 557 (1988).

${ }^{5}$ F. Engelke, J. H. Hahn, W. Henke, and R. N. Zare, Anal. Chem. 59, 909 (1987); J. H. Hahn, R. Zenobi, and R. N. Zare, J, Am. Chem. Soc. 109, 2842 (1987); J. H. Hahn, R. Zenobi, J. L. Bada, and R. N. Zare, Science 239, 1523 (1988).

${ }^{\prime} J$. Grotemeyer, U. Boesl, K. Walter, and E. W. Schlag, Org. Mass Spectrom. 21, 595 (1986); Org. Mass Spectrom, 21, 645 (1986); Org. Mass Spectrom. 22, 758 (1987).

"J. Grotemeyer and E. W. Schlag, Acc. Chem. Res. 22, 399 (1989).

${ }^{8}$ Y. D. Park, T. R. Rizzo, L. A. Peteanu, and D. H. Levy, J. Chem. Phys. 84, 6539 (1986); T. R. Rizzo, Y. D. Park, L. Peteanu, and D. H. Levy, J. Chem. Phys. 83, 4819 (1985).

${ }^{4}$ J. R. Cable, M. J. Tubergen, and D. H. Levy, J. Am. Chem. Soc. 109, 6198 (1987); J. R. Cable, M. J. Tubergen, D. H. Levy, J. Am. Chem. Soc. 110, 7349 (1988).

${ }^{\text {te }}$ P. Arrowsmith, M. S. de Vries, H. E. Hunziker, and H. R. Wendt, Appl. Phys. B 46, 165 (1988): G. Meijer, M. S. de Vries, H. E. Hunziker. and H. R. Wendt, J. Phys. Chem. 94, 4394 (1990); G. Meijer, M. S. de Vries, H. E. Hunziker, and H. R. Wendt, Appl. Phys. B 51, 395 (1990).

"A. Amirav, U. Even, and J. Jortner, J. Chem. Phys. 71, 2319 (1979); J. Phys. Chem. 85, 309 (1981).

"I. Y. Chan and M. J. Dantus, J. Chem. Phys, 82, 4771 (1985).

${ }^{13}$ B. V. Pepich, J. B. Callis, J. D. Sheldon Danielson, and M. Gouterman, Rev. Sei. Instrum. 57, 878 (1986).

${ }^{14}$ T. Imasaka, T. Shigezumi, and N. Ishibashi, Analyst 109, 277 (1984); T. Imasaka, T. Okamura, and N. Ishibashi, Anal. Chem. 58, 2152 (1986).

${ }^{15}$ T, M, Sack and M. L. Gross, Anal. Chem. 55, 2419 (1983).

${ }^{\text {th }}$ M. A. Posthumus, P. G. Kistemaker, H. L. C. Meuzelaar, and M. C. Ten Noever de Brauw, Anal. Chem. 50, 985 (1978).

${ }^{17}$ R. J. Conzemius and J. M. Capellan, Int. J. Mass Spectrom. Ion Phys. 34, $197(1980)$.

${ }^{1 *}$ C. Koster, M. Dey, J. Grotemeyer, and E. W. Schlag, Proceedings of the $38 \mathrm{th}$ ASMS Conference on Mass Spectrometry and Allied Topics, Tucson, AZ, (1990), pp. 1242-1243.

${ }^{10}$ R. M. Caprioli. T. Fan. and J. S. Cottrell. Anal. Chem. 58, 2949 (1986); R. M. Caprioli, W. T. Moore, and T. Fan, Rapid Comm. Mass Spectrom. 1, 15 (1987).

${ }^{20}$ A. E. Asheroft, J. R. Chapman, and J. S. Cottrell, J. Chromat. 394, 15 (1987)

${ }_{21}^{21}$ L. Li and D. M. Lubman, Appl. Spectrosc. 43, 543 (1989).

${ }^{22}$ P. Roepstorff and J, Fohlman. Biomed. Mass Spectrom. 11, 242 (1984).

${ }^{23}$ F. W. MeLafferty, Interpretation of Mass Spectra, 3rd ed. (University Science Books, Mill Valley, CA, 1980).

${ }^{24}$ R. C. Beavis, J. Linder, J. Grotemeyer, and E. W. Schlag, Proceedings of the 36th ASMS Conference on Mass Spectrometry and Allied Topics, San Francisco, CA (1988), pp. 530-531.

${ }^{25} \mathrm{~J}$. R. Eyler, private communication, University of Florida (1990), 